\title{
RELAÇÕES PEDAGÓGICAS E SOCIAIS EXCLUDENTES E TRAUMÁTICAS NA ESCOLA DE ENSINO FUNDAMENTAL: AÇÕES PSICOPEDAGÓGICAS COMO MEDIDAS DE SAÚDE E EDUCAÇÃOO
}

\author{
Maria Claudia Dutra Lopes Barbosa \\ Bacharel e licenciada em Letras - UFRJ; Especialista em Educação Especial - UERJ; Mestre pela Faculdade de \\ Educação - UERJ; Doutora pela Faculdade de Ciências Médicas - UERJ;Professora de Educação Especial \\ FAETEC/RJ;Psicopedagoga;Psicóloga;Terapeuta Cognitivo-Comportamental \\ $\bowtie$ mclaudiadutra@gmail.com
}

\begin{abstract}
Resumo:
O presente trabalho é parte de uma pesquisa realizada em uma escola pública do Rio de Janeiro, objetivando promover reflexões, para futuras intervenções e mudanças na concepção por parte dos docentes do perfil de aluno atendido por instituição pública. Ressalta-se que tal concepção influencia práticas pedagógicas desenvolvidas na mencionada escola. A partir deste dado, buscou-se discutir o atendimento psicopedagógico oferecido àqueles que apresentam problemas de comportamento resultantes de situações familiares ou escolares adversas que produzem dificuldades de aprendizagem, consequentemente, exclusão vivenciada por eles no cotidiano escolar, fato que representa uma questão de Saúde e Educação. Quanto ao material pesquisado, este foi analisado segundo o conceito de Representações Sociais.
\end{abstract}

Palavras-chave: práticas pedagógicas; problemas de comportamento; dificuldades de aprendizagem; exclusão.

\begin{abstract}
:
This essay is part of a research developed in a public school in Rio de Janeiro, presenting the objective to promote reflections that will permit future interventions e changes about the conception of teachers related to student's profile of a public institution. It points out that this conception influences pedagogical practices developed at the mentioned school. According to this data, it is important to discuss psychopedagogical services offered to those who present behavioral disturbance, as a result of familiar or school adverse situations, that promote learning disabilities, consequently, making them to experience daily exclusion at school; a kind of problem of Health and Education systems. Concerning to the researching data, they were analyzed, according to Social Representation concept.
\end{abstract}

Key words: pedagogical practices; behavioral problems; learning problems; exclusion.

\section{INTRODUÇÃO}

As diferentes situações de aprendizagem que ocorrem no cotidiano escolar podem promover ricas experiências coletivas, em razão das interações agradáveis desenvolvidas entre os diferentes atores sociais e o conhecimento em geral Podem estas, entretanto, contrariamente ao esperado, representar um grande sofrimento, segundo Harper et al. (2000), considerando-se os 
intercâmbios sociais inadequados, que não raro, ocorrem entre professores e alunos; alunos e alunos; alunos e demais funcionários de uma escola (DEL PRETTE \& DEL PRETTE, 2005). Ressalta-se, pois, que em virtude de vivências que se processam de forma negativa na escola, sobretudo entre alunos e professores; dificuldades de alguns estudantes em relação ao aprendizado escolar, que resultam em perda de autoestima; fracasso na expressão de comportamentos adequados, socialmente falando, por se apresentarem carregados de agressividade, todos estes fatores podem gerar uma resposta de rejeição por parte de professores e funcionários em geral, tornando a instituição de ensino um lugar de extrema hostilidade, distanciamento e exclusão (MOREIRA \& CANDAU, 2003).

$\mathrm{Na}$ verdade, as experiências sociais escolares deveriam ocupar um espaço do aprendizado acerca dos costumes, falares e tradições dos seus diferentes indivíduos, por serem estes os que trazem, para as salas de aula, a herança pluricultural brasileira (ARROYO, 1997). Sem dúvida alguma, cabe, sobretudo, à escola pública compreender a necessidade de se tratar o tema com a seriedade necessária, pelo fato de que "o critério da justiça curricular é o grau em que uma estratégia pedagógica produz menos desigualdade no conjunto de relações sociais ao qual o sistema educacional está ligado" (MOREIRA \& CANDAU, 2003, p.157).

Opostamente ao esperado, porém, segundo Abramowicz \& Moll (1997), a escola negligencia as diferenças entre seus estudantes, ao buscar uma homogeneidade de seres e saberes que não é possível. Assim procedendo, ao longo de décadas, a instituição de ensino regular vem atuando, ainda que de modo subliminar, reforçando o domínio de um grupo social sobre os outros, legitimando o discurso e a ideologia da classe dominante, dificultando o reconhecimento da alteridade dos segmentos desfavorecidos, sobretudo os de etnia negra, neste espaço social (AMORIM, 2011).

A partir desta conduta, a instituição escola inviabiliza a comunicação e o intercâmbio de experiências entre indivíduos, domando gestos e corpos e descredenciando valores, conforme lembra Foucault (1979), consequentemente, contribuindo para a fragmentação dos grupos sociais (GARCIA, 2001).

Considerando-se o exposto acima, é importante destacar que o processo de exclusão, negligência e abandono conferidos pela sociedade brasileira aos segmentos sociais desfavorecidos, especialmente negros e mestiços, tem acarretado inúmeros problemas sociais visíveis, ao se ponderar que "a relação entre questões relativas à justiça, redistribuição, superação das desigualdades e democratização de oportunidades e as referidas ao reconhecimento de diferentes grupos culturais se faz cada vez mais estreita" (CANDAU, 2008, p.45). 
Endossando as palavras ditas acima, é no seio da escola onde se faz sentir, com propriedade, esta exclusão, quando as pesquisas demonstram que havendo, no mínimo um episódio de reprovação escolar, o quantitativo de retenção de crianças negras chega a atingir 66\% (ABRAMOVICZ \& MOLL, 1997); fato, que segundo as autoras mencionadas, conta com o não conhecimento dos professores sobre a questão (IDEM, 1997).

O fato acima expresso requer uma reflexão mais acurada, sobretudo considerando-se que a esmagadora maioria de professores trabalha em mais de uma jornada, que se dá em diferentes escolas, sob uma forma de trabalho alienante, e recebendo salários aviltantes. No que tange a esta questão, sabe-se que este professor "está irremediavelmente sozinho, desarticulado, destacado de uma rede de sustentação que o remeta a uma tradição, que o prestigie e atribua significação à sua prática" (KUPFER, 1998, p. 168).

$\mathrm{Na}$ verdade, as relações que se estabelecem entre professores e alunos se fazem permeadas pela reificação de ambos (TREVISAN, 2011). Se por um lado o professor, segundo Fonseca (2009), esvaziado da importância social de seu papel, apartado do diálogo com suas instituições de ensino, em razão de processos gerenciais advindos de orientações governamentais superiores, há o aluno, indivíduo tomado como massa a ser modelada, "usinada", segundo o Dicionário Michaelis (1998), submetida, enquanto material em estado bruto, à ação de uma máquina ou de uma ferramenta, a fim de ser trabalhado, até atingir o processo final.

Adicionado aos fatores descritos acima, no que tange ao alunado, destaca-se a gravidade da realidade de vida destas crianças e adolescentes pesquisados, que, usualmente, habitam áreas de risco, nas quais presenciam cenas de morte, por meio de assassinatos; violência diária, tais como espancamento, parte de seus pais, padrastos ou pessoas que exercem a função parental; abuso sexual; abandono; negligência, entre outras situações patológicas experimentadas. Todos estes fatores, evidentemente, contribuem para um desempenho social e escolar comprometidos, conforme destaca Candau (2008).

Similarmente aos estudantes pesquisados, vale destacar que um expressivo número de estudantes de classes favorecidas ou desfavorecidas, sempre que revela algum tipo de dificuldade de aprendizagem, costuma ganhar o rótulo de desinteressado e preguiçoso para aprender (ABRAMOVICZ \& MOLL, 1997).

Inegavelmente, problemas se fazem sentir nas interações entre os sujeitos oriundos dos diferentes segmentos sociais que frequentam a escola, estando entre estas, aquelas pertinentes à dificuldade de encontrarem coisas comuns entre si; a exposição destes sujeitos a métodos de leitura, escrita e cálculos inadequados; o ensino dissociado da realidade socioeconômica e cultural destes educandos, resultando em sucessivas repetências; os comportamentos por estes 
produzidos, os quais não se fazem aceitos, socialmente falando; as agressões ocorridas entre colegas, estudantes e professores, estudantes e funcionários; a infração às regras institucionais, no mais das vezes, concebidas sem a participação dos sujeitos educandos, por refletirem apenas o desejo dos estabelecimentos (DEL PRETTE \& DEL PRETTE, 2005). Enfim, os repetidos fracassos experimentados pelos estudantes de classes desfavorecidas, resultando no trágico quadro cotidiano das escolas brasileiras (GARCIA, 2001).

\section{SUJEITOS DA PESQUISA}

Objetivando explicitar as questões já abordadas, as linhas abaixo oferecerão um primeiro quadro de sujeitos que apresentam alguns problemas de aprendizagem e comportamento:

\begin{tabular}{|c|c|c|c|c|}
\hline Sujeitos & Idade & Ano & Problema Apresentados & Comportamento \\
\hline 01 & 06 anos & $1^{0}$ & Nec. Especiais (S. Down) & Falta de Limites e Agressividade \\
\hline 02 & 07 & $1^{\circ}$ & TDAH? & Agressividade e Mentiras \\
\hline 03 & 05 & $1^{\circ}$ & TDAH? Transt. Desaf. & Fúria, Agressão e Comp. Desafiador \\
\hline 04 & 06 & $1^{\circ}$ & Baixo Rend. TDH? & Agressividade e Comp. Desafiador \\
\hline 05 & 06 & $2^{\circ}$ & DA? & Falta de Limites \\
\hline 06 & 08 & $3^{0}$ & DA? & Desinteresse e Apatia \\
\hline 07 & 10 & $5^{\circ}$ & Transtorno Desafiador? & Impulsividade e Agressividade \\
\hline 08 & 15 & $8^{\circ}$ & $\begin{array}{r}\text { Dific. Aprend, Falta de Asseio duas } \\
\text { vezes Reprovado }\end{array}$ & Insinua-se sexualmente $\mathrm{p} /$ colegas* \\
\hline 09 & 15 & $8^{\mathrm{a}}$ & Não lê/escreve, (quatro Rep. $9^{\circ}$ ano) & Agressividade $* *$ \\
\hline 10 & 15 & $8^{\mathrm{a}}$ & Rep.(duas vezes a $8^{\mathrm{a}}$ ano) & Alterna Apatia e Agressividade \\
\hline
\end{tabular}

a) * sujeito 08 - A psicóloga escolar suspeita de abuso sexual por parte do pai, porém não pode comprovar.

** sujeito 09- É pai aos 15 anos.

b) TDAH - transtorno do Déficit de Atenção e /ou Hiperatividade, DA - Déficit de Atenção.

No quadro acima, observa-se que os sujeitos, em sua maioria, apresentam comportamento agressivo, seguido pela manifestação do desafio às regras e ordens criadas pela instituição, passando pela apatia e pelas dificuldades de aprendizagem (CORREIA, 1991). Alguns apresentam comportamento sugestivo tanto de TDAH - Transtorno do Déficit de Atenção/Hiperatividade como de DA - Déficit de Atenção. Estudos desenvolvidos na área da Neuropediatria apontam causas multifatoriais, entre elas, a existência de parentes ou um dos pais com TDAH, entre outras causas ligadas à presença do transtorno em determinadas crianças e adolescentes (BARKLEY, 2002). 
Quanto aos sujeitos da pesquisa, porém, estes passaram ou passam alguma forma de abuso ou abandono, seja emocional, físico ou psicológico. Tais comportamentos são citados pela National Child Traumatic Stress Network - NTSN (2006), onde encontramos dados que descrevem comportamentos causadores de trauma, com sendo todos aqueles que afetam o sujeito fisicamente, emocionalmente, psicologicamente, e academicamente. Quanto à forma como estas pessoas vão reagir às experiências traumáticas, dependerá da idade e nível de desenvolvimento dos mesmos.

No que tange às consequiências do trauma sobre o aprendizado em relação aos estudantes do primeiro segmento do Ensino Fundamental ( $1^{\circ}$ ao $5^{\circ}$ ano), a NTSN nos adverte que estes educandos podem apresentar estresse, acompanhado por manifestações corporais, tais como: dores de estômago, dores de cabeça e dores em geral. Podem estes, do mesmo modo, demonstrar mudanças de comportamento, como irritabilidade aumentada, agressividade e manifestações de raiva. Quanto aos estudantes do segundo segmento do Ensino Fundamental (da $6^{\circ}$ à $9^{\circ}$ ano), mais conscientes de sua realidade, estes tendem a experimentar sentimentos de culpa, vergonha ou fantasias de vingança. Alguns deles podem revelar mudança de comportamento na família ou escola, assim como virem a se envolver em comportamentos de autodestruição. Destaque-se que estes estudantes costumam revelar mudanças no desempenho escolar e baixa frequência à escola.

No tocante à opinião dos professores em relação aos problemas de comportamento e aprendizagem dos estudantes do quadro 1 , as falas contidas no quadro 2 , logo a seguir, podem melhor ilustrá-las:

\begin{tabular}{|c|c|}
\hline Sujeitos & Avaliação dos Estudantes e suas Famílias por parte dos Professores \\
\hline 01 & $\begin{array}{l}\text { "Ela não tem limites, a família é negligente, desestruturada. A mãe não quer nada, quem cuida dela, } \\
\text { eu sei, é a irmã de } 14 \text { anos!" }\end{array}$ \\
\hline 02 & "Nunca vi criança igual, não pára nunca, além disso, diz que o pai, que é segurança, tem carro zero!" \\
\hline 03 & $\begin{array}{l}\text { "A mãe diz que ele não faz nada disso em casa. As outras mães estão fazendo abaixo-assinado } \\
\text { para ele sair da turma, porque ele bate em todas as crianças." }\end{array}$ \\
\hline 04 & $\begin{array}{c}\text { "Este menino só pode ser hiperativo, ele é um horror de movimentação e agressividade! Ele é criado } \\
\text { pela avó que diz que é mãe, porque o menino perdeu a mãe, quando nasceu. } \\
\text { O pai, por causa disso, rejeitou o menino." }\end{array}$ \\
\hline 05 & $\begin{array}{l}\text { "O fulano é filho de mãe velha. Ele é adotado e sem limites. Ele é dessas crianças cheias de vontade } \\
\text { que fazem o que querem. Na verdade, ele é imaturo." }\end{array}$ \\
\hline 06 & $\begin{array}{c}\text { "Ela não aprende nada, é apática e desinteressada. Não para na mesma cadeira por muito tempo. A mãe exige muito desta } \\
\text { menina. Ela bate mesmo!" }\end{array}$ \\
\hline 07 & $\begin{array}{c}\text { la é debochada, respondona e não respeita ninguém. Ela esfregou o caderno na cara da professora. Diz a orientadora que o } \\
\text { pai dela morreu a pauladas. Ele era ex-presidiário. Que horror!" }\end{array}$ \\
\hline 08 & $\begin{array}{l}\text { Ela não toma banho e cheira mal. Ninguém quer ficar perto dela. Não aprende, e parece que o pai abusa sexualmente desta } \\
\text { menina. Ela vive se oferecendo para os meninos. A avó é omissa e a mãe foi embora. }\end{array}$ \\
\hline
\end{tabular}




\begin{tabular}{|c|c|}
\hline & É uma família desestruturada. É tudo muito triste." \\
\hline 09 & "Imagine você que este menino quer trabalhar com arma, para poder atirar. Fiquei sabendo que tem uma \\
& filha de um mês!" \\
\hline 10 & "Este aí nunca vai andar para frente, porque a mãe quer que a escola se adapte a ele e não ele à escola." \\
\hline
\end{tabular}

Os maiores problemas apresentados pelos educandos da pesquisa, nas observações dos professores, tais como: nas famílias de muitos de seus alunos, que deles abusam, seja física ou emocionalmente; na omissão e desestruturação destas famílias; no meio social deficitário, em termos de estímulos intelectuais; no comportamento desviante dos estudantes, quando comparado ao padrão esperado, porque carentes de um modelo educacional familiar adequado, desconhecem regras sociais e maneiras adequadas de ser comportarem em diferentes espaços sociais (CABALLO, 2002). Esta forma de pensar coincide com pesquisas as quais corroboram a visão estereotipada de aluno fracassado, "visto como diferente ou deficiente...", e de sua família, “... considerada desinteressada e desestruturada, portanto, incompetente para educá-lo e acompanhá-lo nas tarefas escolares” (ABRAMOWICZ \& MOLL, 1997, p. 37).

Aliado a todos os dados acima descritos, o aumento da violência, fruto de uma sociedade desigual e desarticulada, vem contribuindo para tonalizar, intensamente, o quadro de abandono e perda de status das instituições escolares (LUCINDA; NASCIMENTO \& CANDAU, 2001).

Vista, em idos tempos, como a única possibilidade de se romperem as desigualdades sociais, a escola, atualmente, sofre o mesmo desprestígio que o professor, figura refém do tempo, de pressões sociais, de alunos desafiadores, de famílias que não cumprem seu papel, conforme adverte Zagury (2006).

Deve-se ressaltar que esta forma de conceberem os papéis sociais diz respeito às concepções que cada integrante de um grupo social tem do outro, tocando, pois, a esfera das Representações Sociais (MINAYO, 1999). Buscando focalizar tais questões, prosseguir-se-á na pesquisa, abordando elementos pertinentes à análise dados da mesma.

\section{MÉTODO}

O método utilizado para analisar os dados da pesquisa baseou-se na Teoria das Representações Sociais que afirma ser necessário compreender como a sociedade se representa a si e ao mundo que a rodeia, constatando que se “... ela aceita ou condena certos modos de conduta, é porque entram em choque ou não com alguns de seus sentimentos fundamentais, sentimentos estes que pertencem à sua constituição" (MINAYO, 1999, p. 91). A maneira como se julga o comportamento de um sujeito encontra respaldo nas concepções criadas no tecido 
social. Assim sendo, o outro que se olha, revela ao nosso olhar todas as formas e conceitos para enquadrá-lo em critérios nossos, “... para submetê-lo a todas as nossas práticas” (LARROSA, 1998, p. 09).

Corroborando esta afirmativa, diz-se, enquanto concepção de aluno bem-sucedido, segundo professores, os que demonstram responsabilidade, obediência, disciplina e esforço, atributos que o enquadram no conceito de "aluno nota 10" (RANGEL, 2000). Já na concepção do aluno, um bom professor torna a matéria simples, sem complicações; fornece explicações, sempre que necessário; é paciente para responder, quando o aluno lhe faz perguntas; tem habilidades para ensinar de diferentes maneiras, até que o aluno diga que aprendeu (IDEM, 2001).

\section{RESULTADOS E DISCUSSÃO}

Considerando-se as intervenções psicopedagógicas dirigidas aos estudantes aqui apresentados, deve-se destacar que todo o trabalho ofertado foi direcionado a mediar melhores interações entre os sujeitos em questão e seus pares, no âmbito escolar; entre estes sujeitos e seus professores; entre estes mesmos sujeitos e seus familiares (SOLÉ, 2001). Em relação ao sujeito 01, com necessidades educacionais especiais, em particular (Síndrome de Down), seu aprendizado, embora mais lento, em virtude da síndrome, contava com a parceria casa-escola, quanto ao estabelecimento de regras. A partir da maior atuação da mãe, o quadro da criança revelou substancial melhora. $\mathrm{O}$ sujeito 02 reconhecia sua condição social de carente, mas não aceitava o fato, inventando a existência de carros zero para o pai, um segurança. Um trabalho de apoio e valorização da sua família auxiliou a melhorar seu quadro. O sujeito 03 precisava conhecer a autoridade materna, assim sendo, trabalhou-se, em termos de orientação educacional familiar. O sujeito 04 apresentava um quadro de ansiedade, movimentação, agressão e ressentimento, por não ver o pai e se sentir rejeitado. As questões pertinentes ao comportamento inadequado do sujeito no convívio com colegas vêm sendo trabalhadas, enquanto os problemas familiares são tratados em terapia, fora da escola. O sujeito 05 se mostra paralisado, quando é cobrado a executar qualquer tarefa, assim sendo, enquanto trabalho em andamento, as estratégias de negociação se revelaram como a melhor opção. O sujeito 6 mostrava apatia e desinteresse, mas somente em relação ao que não gostava de fazer. Valorizar seu potencial e fazê-lo crer em si auxiliou-o a vencer barreiras. $\mathrm{O}$ sujeito 07 revelava grande potencial e inteligência acima da média, e, para auxiliá-lo, um trabalho de parceria casa-escola, explorando talentos e respeito às diferenças auxiliaram-no bastante. Quanto ao sujeito 08, que apresenta dificuldade em construir 
uma autoimagem positiva, a parceria com a família e o estudante, buscando resgatar-lhe a autoestima vem revelando um grande progresso, mesmo que lento. $\mathrm{O}$ sujeito 09 convive com a dualidade da responsabilidade de ser pai e ser adolescente, e ainda se mostra retraído. Finalmente, o sujeito 10 se esconde na atitude superprotetora de sua mãe que não sabe, mas obtém ganhos secundários na dependência do filho em relação a ela.

\section{CONSIDERAÇÕES FINAIS}

Tratando-se de segmentos sociais desfavorecidos, como os que são apresentados neste trabalho, convém destacar que aqueles aqui descritos pertencem ao universo dos que desejam encontrar, como tantos outros, a aceitação de sua pessoa no olhar, nas palavras e gestos emitidos pelos pais, professores e colegas com os quais convivem. Assim sendo, ressalta-se que a identidade social de um sujeito também se constrói na escola, pois não sendo um ser autárquico, o homem depende de outros para existir (ARENDT apud LUCINDA, NASCIMENTO \& CANDAU, 1998).

Reforçando este pensamento, deve-se destacar que toda e qualquer forma de preconceito precisa ser discutida com o grupo, dentro da escola, que vai trabalhar, democraticamente, para desfazê-lo. Assim sendo, defesas de argumentos emitidos por alguns professores que insistem em estabelecer comparações entre suas histórias de vida e as de seus alunos, dizendo que também vieram de "meios carentes", não deixando, por isso, de estudar, esbarram em resistências a outros argumentos explicativos, que tentam lhes dizer que estas crianças vivem no meio de uma guerra urbana, e que são tratadas como cidadãos "invisíveis" para as instâncias do Estado. Reitera-se a argumentação, dizendo que muitos deles, professores, certamente não passaram pelas cenas de violência, morte e abusos que muitas destas crianças vivenciam, cotidianamente.

Enfim, termina-se este trabalho, com a sugestão de que mais pesquisas na área sejam desenvolvidas, de modo a contribuírem para o desfazimento de crenças e preconceitos que afastam estudantes, mestres, famílias e escola, a fim de que contribuam para desfazer a distância que os separa. 


\section{REFERÊNCIAS}

ABRAMOWICZ, A., MOLL, J. (Orgs.) Para além do fracasso escolar. S/ed., Campinas, SP: PAPIRUS, 1997, 208 p.

AMORIM, R. $\mathbf{M}^{\mathrm{a}}$ de $\mathrm{O}$ (A) negro (a) na sociedade brasileira ontem e hoje: o papel das categorias raça, etnia e classe social para a educação escolarizada Revista Lugares de Educação, Bananeiras, v. 1, n. 1, p. 87-106, jan.-jun. 2011 ISSN 2237-1451 Disponível em http://periodicos.ufpb.br/ojs2/index.php/rle Acesso realizado em 01 de junho de 2013.

ARROYO, M. Fracasso-sucesso; o peso da cultura escolar e do ordenamento da educação básica. In: ABRAMOWICZ, A., MOLL, J. (Orgs.), S/ed., Campinas, SP: PAPIRUS, 1997, 208 p.

BARKLEY, R. A. O que causa o tdah? In Transtorno do déficit de atenção e hiperatividade (tdah). S/ed.: Porto Alegre, RS: ARTMED, 2002, 327 p.

CABAllo, V.Manual de técnicas de terapia e modificação do comportamento. São Paulo: Santos, 2002, 873 p.

CANDAU, V. Ma Direitos humanos, educação e interculturalidade: as tensões entre igualdade e diferença Revista Brasileira de Educação v. 13 n. 37 jan./abr. 2008.

CORREIA, L. M. Dificuldades de aprendizagem: contributos para a clarificação e unificação de conceitos. S/ed.: Porto, Portugal: Editora Associação dos Psicólogos Portugueses, 1991, s/p.

DELORS, J. Da comunidade de base à sociedade mundial In: Educação: um tesouro a descobrir. $8^{\mathrm{a}}$ ed., São Paulo: CORTEZ, Brasília, DF, MEC; UNESCO, 2003, 287 p.

DEL PRETTE , Z.A. P.; DEL PRETTE, A. Psicologia das habilidades sociais na infância: teoria e prática. $1^{\text {a }}$ ed., Petrópolis, Rio de Janeiro: Vozes, 2005, 270 p.

FOUCAULT, M. Microfísica do poder. Organização e tradução de Roberto Machado. 25a , Rio de Janeiro: Edições Graal, 1979, 174 p.

GARCIA, R, L. Currículo emancipatório e multiculturalismo: reflexões de viagem. In: Territórios contestados. 5a ed., Petrópolis, Rio de Janeiro, Vozes, 2001, 202 p.

HARPER, B; CECCON, C; de OLIVEIRA, M. D.; de OLIVEIRA, R. D., Cuidado, escola: desigualdade, domesticação e algumas saídas. 35a ed., São Paulo: BRASILIENSE, 2000, 119 p. KUPFER, M. C. A violência na educação: Educação violenta. In (Org.) D. L. Levisky, Adolescência pelos caminhos da violência. São Paulo: Casa do Psicólogo, 1998, 200 p.

LARROSA, J. Prefácio e a propósito do outro: a loucura. In Imagens do Outro. S/ed., Petrópolis, RJ: VOZES Ed., 1998, 200 p. 
LUCINDA, M. C.; NASCIMENTO, M. G.; CANDAU, V. Escola e violência. $2^{\mathrm{a}}$ ed., Rio de Janeiro: DPA Ed., 2001, 103 p.

MINAYO, M. C. S. O conceito de representações sociais dentro da sociologia clássica. In: Textos em representação social. $5^{\text {a }}$ ed., Petrópolis, RJ, VOZES Ed., 1995, 324 p.

MICHAELIS Moderno dicionário da língua portuguesa. São Paulo: Companhia Melhoramentos (Dicionários Michaelis), 1998, 2259 p.

MOREIRA, A. F. B.; CANDAU, Vera Maria Educação escolar e cultura(s): construindo caminhos. Revista Brasileira de Educação. Maio/Jun/Jul/Ag., n. 23, 2003.

$\begin{array}{llll}\text { NATIONAL } & \text { CHILD } & \text { TRAUMATIC } & \text { STRESS }\end{array}$ http://www.nctsn.org/nccts/nav.do?pid=ctr_aud_schl_effects\#q7

RANGEL, M. Representações e reflexões sobre o bom professor. $8^{\mathrm{a}}$ ed., Petrópolis, RJ: VOZES Ed., 2001, 92 p.

SOLÉ, I. Orientação educacional e intervenção psicopedagógica. S/ed., Porto Alegre, RS: ARTMED Ed., 2001, 166 p.

TREVISAN, A. L. Formação ou reificação?: a educação entre o mesmo e o outro. Educ. Soc., Campinas, v. 32, n. 117, Dec. 2011 .

Available from <http://www.scielo.br/scielo.php?script=sci_arttext\&pid=S010173302011000400016\&lng=en\&nrm=iso $>$. Access on 02 June 2013. http://dx.doi.org/10.1590/S0101-73302011000400016.

ZAGURY, T. Algumas considerações pedagógicas sobre a história da crise. In: O professor refém. S/ed., Rio de Janeiro: RECORD, 2006, 301 p. 